\title{
IMPACT OF SOIL EROSION ON WATER QUALITY IN THE HATTA DAM (DUBAI EMIRATE)
}

\author{
LALA EL HOUMMAIDI ${ }^{1} \&$ Dr. ABDELKADER LARABI ${ }^{2}$ \\ ${ }^{l}$ GIS Centre, Dubai Municipality, Dubai, United Arab Emirates \\ ${ }^{2}$ Laboratory Analysis and Modeling of Water and Natural Resources (LAMERN) Mohamed V University,
}

Mohammadia School of Engineers, Rabat, Morocco

Serious soil erosion challenges are faced in Dubai as a result of its erosion-prone land forms and climate, along with major urban expansion activities which have an adverse impact on surface water bodies. Therefore, sediment control and soil conservation measures are necessary.

The objective of this study is to evaluate the impact of soil erosion in the hilly area of Hatta geospatially and quantitatively, identify the main erosion factors and how to prevent or mitigate them.

Because the soil erosion models are crucial estimation tools to extrapolate and predict the erosion risk, the Revised Universal Soil Loss Equation (RUSLE), which predicts annual soil loss from rainfall and runoff, was used for this particular study due to its relatively robust structure and empirical basis.

The results established throughout this project support locating potential areas of sediment production and reveal the erosion causes on water bodies affecting its quality.

This study delivers also its outputs as a genuine comparison maps for displaying spatial distributions of soil erosion losses under different cover and management practices which is very important for planners and decision makers to better design solutions to counteract the effect of water erosion and its impact on the Hatta dam water retention.
\end{abstract}

KEYWORDS: RUSLE, GIS, Water Erosion, Hatta Dam, Soil Mapping, Soil Erosion \& Land Degradation

Received: Aug 16, 2018; Accepted: Sep 06, 2019; Published: Oct 16, 2019; Paper Id.: IJCSEIERDDEC20191

\section{INTRODUCTION}

There is evidence that most of the water resources are undergoing degradation in an accelerating rate. The situation in Dubai Emirate is a witness of the same. Furthermore, Dubai being located in an extremely arid desert belt, with expanding population, extensive agricultural production, as well as rapid urban expansion, its extensive soil erosion consists of major problems leading to several critical environmental issues. The eroded material from soil erosion causes major local and global effects that are damaging the both flora and fauna. These variety of these effects could be increased by inter and intra reactions within the ecosystem.

Soil is ultimately crucial to terrestrial ecology and is vital to socio-economic development. Thus, information on soils with regard to their texture, nature, extent and spatial distribution along with their potential and limitations is required for variety of uses, such as smart agricultural planning, sustainable development, urban activities, etc. Inaddition, such information is critical for modeling and environmental impact analysis. 


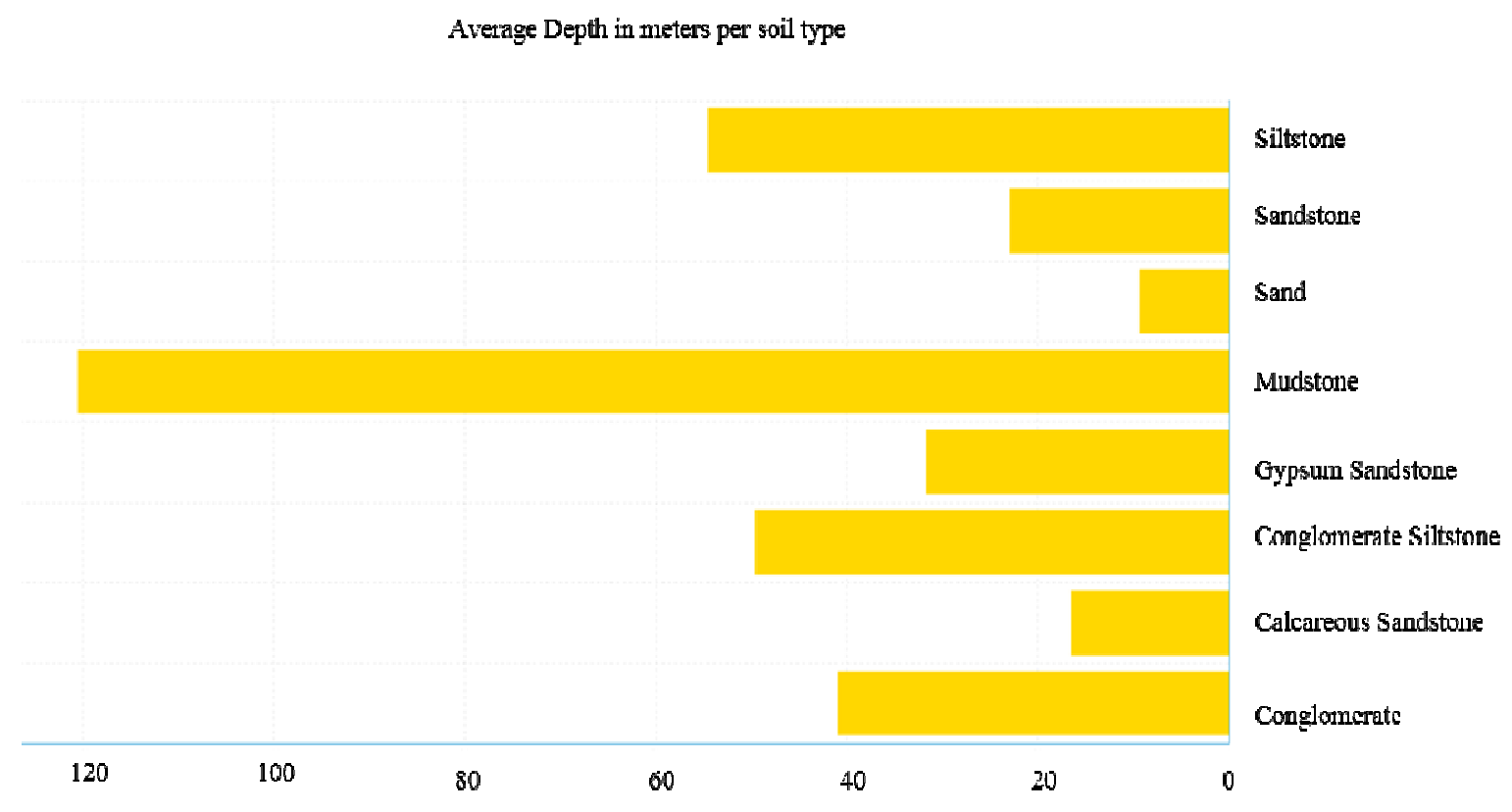

Figure 1: 8 Main Soil Classes Subject of the Study.

The remote sensing extracted the datasets along with the compilation of all boreholes data available at Dubai Municipality was used to map soil information with the support of smart field mapping devices. In 2018, using the land use map, 60,000 km2 was covered and boreholes locations were determined to serve as the primary field destinations of the main soil inventory and survey.

The main classes of this study focus on 8 soil classes which are captured and described in details during the drilling projects undertaken by Dubai Municipality for different purposes such as: strategic sewerage tunnel planning, Dubai Soil Information System, Dubai 3D Data, Dubai Groundwater model, etc. These classes are respectively, sand, calcareous sandstone, sandstone, gypsums and stone, conglomerate, conglomerates iltstone and finally silt stone then mudstone.

The erosion phenomenon in Dubai occurs at a rapid rate which causes a great loss of the surface soil, reduction of the crop potential and contamination of surface water and groundwater networks. Thus, soil erosion is one of the most adverse environmental concerns for Dubai government, not only because it causes deprivation of soil nutrients and land degradation, but also leads to many serious environmental issues such as water siltation, and water resources pollution. The soil erosion process is becoming a major obstacle against the sustainable development program. Dubai is extensively working on, which eventually calls for ultimate monitoring and evaluation.

The objective of this study is to analyze and assess geospatially the factors affecting soil erosion and degradation and how to control and mitigate the mat the area of Hatta. This study is focused on using the GIS capabilities along with the advanced RUSLE models as a multi-criteria method to map the various factors contributing to the erosion process in Hatta including rainfall, lithology, topography, vegetation cover, etc. then disseminate the soil vulnerability levels to erosion in different formats which will be very useful for planners and decision makers to meet the sustainability criteria required by the government.

\section{Study Area}

Hatta is located approximately at $134 \mathrm{~km}$ south-east of Dubai City. It is situated relatively high in the Hajar Mountains, surrounded by Oman borders from the east and south, Ajman exclave of Masfoutfrom the west, and Ras al-Khaimah from the north. 


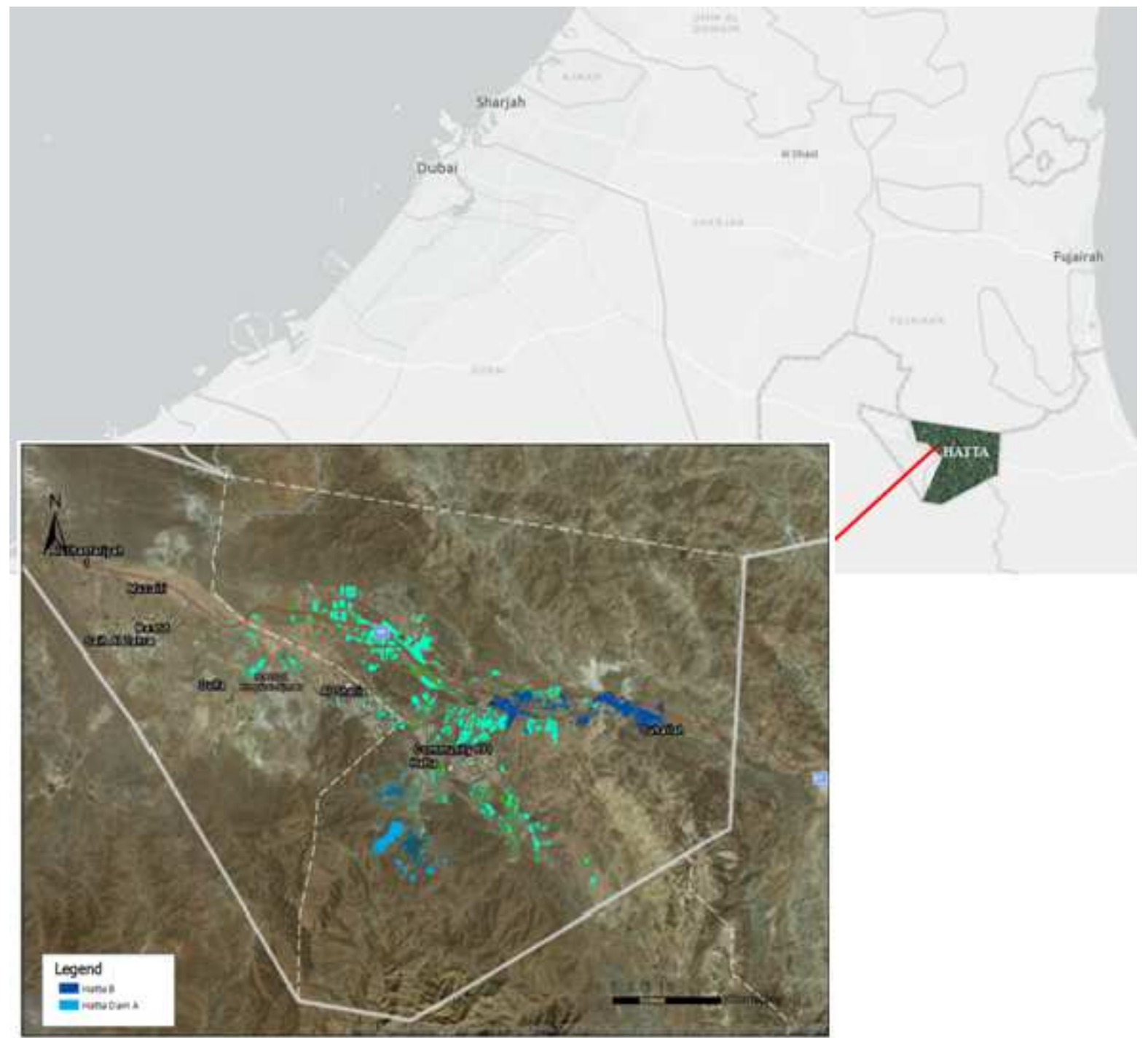

Figure 2: Hatta's Geographical Location Versus Dubai Emirate.

Hatta is characterized by structural valleys, piedmont area residual hills, and denudation hills consisting of Periodite, Dunite, Gabbro, Limestone, Dolomite, and Marble along with other structural hills.

The soil temperature in Hatta is hyper thermic, while the soil moisture is arid. Based on the collected samples, during boring activities at Hatta, the soils are considered in general calcareous.

Even though, the dams in Dubai are small, they are critical for water supply and enhancement of groundwater quality. Hatta Dam for example is one of the most important dams in the Emirate which is located relatively high in the Hajar Mountains. The First and Second Hatta Dams that were built at a cost of \$25 million have a total storage capacity of around $20 \mathrm{MCM}$ of rainwater. Thus, it is considered as a very rare reserve of surface water in Dubai constructed mainly to control and supply the plantations and dwellings of the region.

A decent amount of rainfall in non-arid climate is capable of recharging groundwater tables and filling dams. However, in Dubai, the evaporation rate of surface water is relatively high and catchment areas have different surface characteristics that make water penetration a challenge. Refilling Hatta's groundwater is important as it is estimated to run dry by 2030 according to the studies carried by Dubai Municipality. 


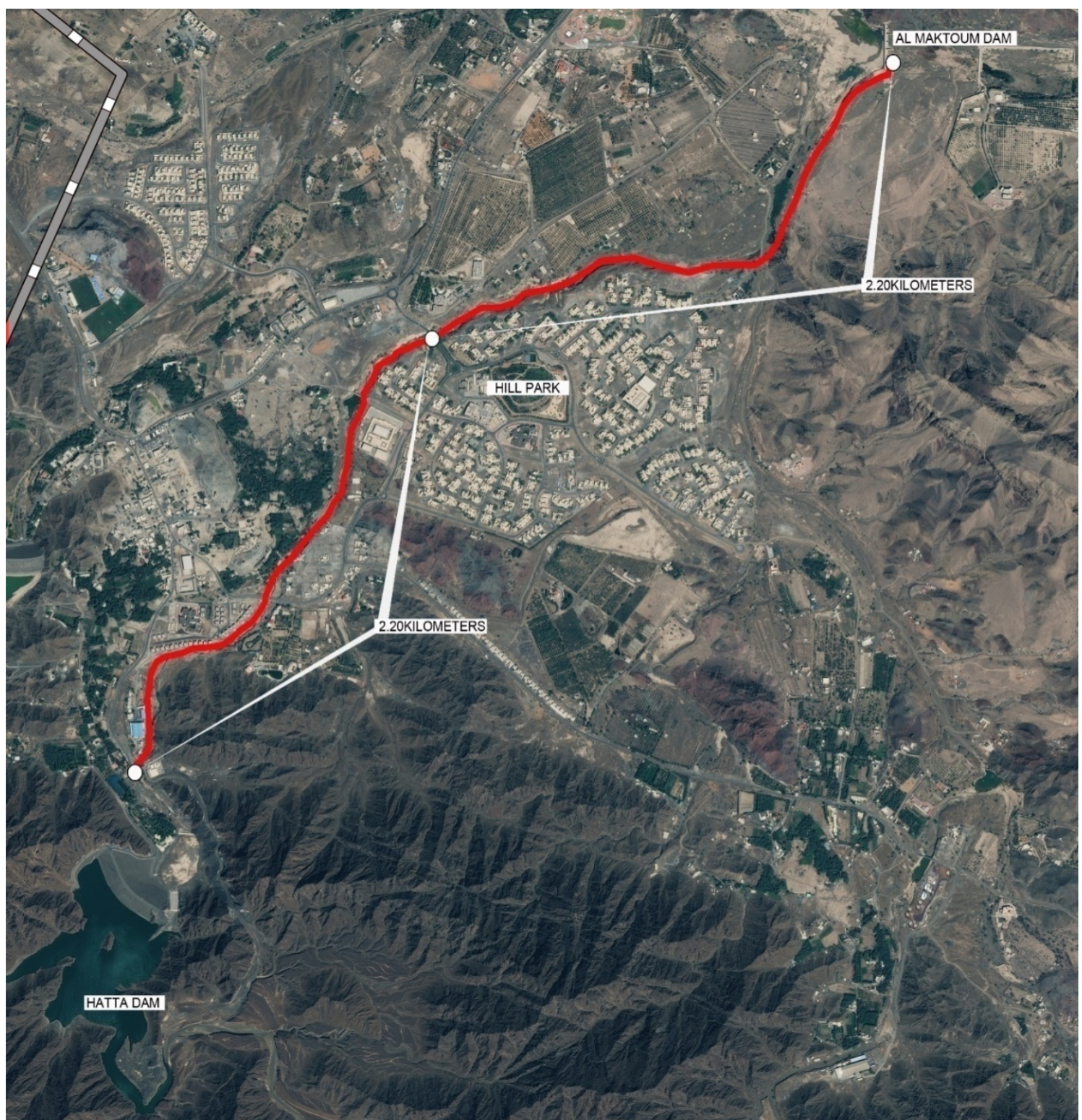

Figure 3: Walkthrough from Hatta Dam to Al Maktoum Dam via Wadi Al Dhara.

The elevation in Hatta varies between $50 \mathrm{~m}$ and 3,000 $\mathrm{m}$ and the central section of the Al-Hajar Mountain is considered the highest and wildest terrain in the country. Jebel Akhdar $(3,075 \mathrm{~m})$ is the highest of the range followed by Jabal Shams (3,009m). The latter and the smaller Jebel Nakhl range are bounded on the east by the low Sama'il Valley.

Geologically, Al-Hajar Mountains are the extension of Zagros Mountains that were formed in the Miocene and Pliocene as the Arabian Plate collided with and pushed against the Iranian Plate. The main soils of these mountains are Cretaceous Limestone and Ophiolite. The mountains begin in the Musandam Peninsula, and extend about $440 \mathrm{~km}$ to Ras Al-Hadd East, resulting to $50 \mathrm{~km}$ wide. This range is one of the very rare places worldwide where less dense oceanic crust is located below more dense oceanic crust and upper parts of the Earth's layer, and thus has Ophiolite exposed, like the Andes, Himalayas, Swiss Alps and other ranges.

The climate at the low coastal land north and east of the Jebel Hajar is cool and wet from December to March, and warmer but occasionally rainy from April to September. 


\section{MATERIALS AND METHODS}

The figure 4 summarizes the entire study process and methodologies involved in this project including the literature review and the field survey conducted by different teams where the samples of sediments had been collected at representative scales of the study area during main boreholes drilling projects managed by Dubai Municipality. The next step focuses on the analysis of soil erosion activities and other pollution sources in Hatta dams using GIS tools and python scripts. One of the most important steps of this process is the modelling of the soil erosion, therefore, The RUSLE erosion method was chosen to generate soil loss raster for sheet and rill erosion. The cartographic representation of the different factors and parameters of the erosion along with the water quality are also important and covered in this study. Finally, further analysis is carried out to examine the link between the soil erosion and water quality by identifying the relevant dominant factors.

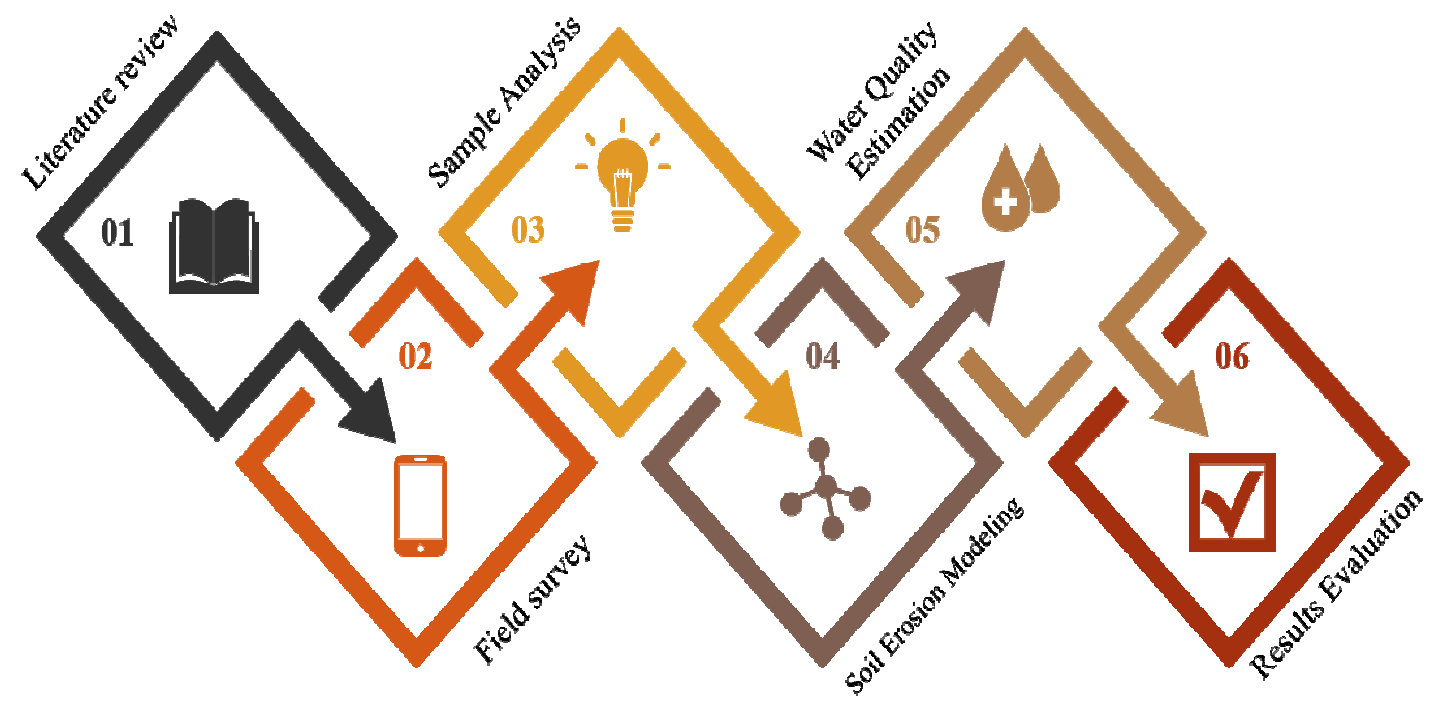

Figure 4: Study Process.

\section{Field Work}

Field surveys were undertaken by Dubai Municipality, to collect important information about soils and associated land features.

Model flow Map Mobile-GIS Solution was the main tool used to report the boreholes information during boring activities. The results of these surveys supported also in calibrating the Hatta groundwater models since groundwater parameters of water wells were also collected during the field work. Furthermore, irrigation activities information in the crops were recorded and stored within the main datasets of the project. The following list describes the parameters collected during the soil and well boring activities:

Table 1: Collected Information at every Borehole and well as Samples of the Project

\begin{tabular}{|l|l|}
\hline \multicolumn{1}{|c|}{ Soil Boring Information } & \multicolumn{1}{c|}{ Well Information } \\
\hline Borehole Number & Unique ID of the well \\
\hline Project Name/Project Reference & Facilities available along with asset barcodes \\
\hline Project Location & Well Type \\
\hline Boring coordinates (Longitude, Latitude in DLTM) & Well coordinates (Longitude, Latitude in DLTM) \\
\hline Start/End date and time & Start/End date and time \\
\hline Type and depth of boring & Water quality level \\
\hline Boring and Core Diameter & Well Depth \\
\hline Casing Diameter and Depth & Water Depth \\
\hline Total Depth & Well Dimensions \\
\hline
\end{tabular}




\begin{tabular}{|l|l|}
\hline \multicolumn{2}{|c|}{ Table 1: Contd., } \\
\hline Ground Level & Casing Material \\
\hline Drilling Method & Volume of Water per well volume \\
\hline Water Depth & Tubing Material \\
\hline Sampling method and sample type & Pump set \\
\hline Soil Density and Consistency & Weather Conditions \\
\hline Soil Colour (mottling, abundance, size and contrast) & Pumping rate during sampling \\
\hline Volume pumped during sampling & Dissolved Oxygen (DO) in mg/l \\
\hline Grain size in Particle Size Distribution (PSD) & Specific Electrical Conductance $(\mu \mathrm{S} / \mathrm{cm})$ \\
\hline Particle shape & Oxidation-reduction potential $(\mathrm{ORP})$ \\
\hline Classification & Turbidity (NTU) \\
\hline Sedimentary structure & PH Value \\
\hline Core Recovery & Temperature $(\mathrm{C})$ \\
\hline Layer boundaries and thickness (transition soil types) & Notes (Sketch on Picture or Map) \\
\hline Plasticity & Photos \\
\hline Moisture & \\
\hline Thickness & \\
\hline Photos & \\
\hline
\end{tabular}

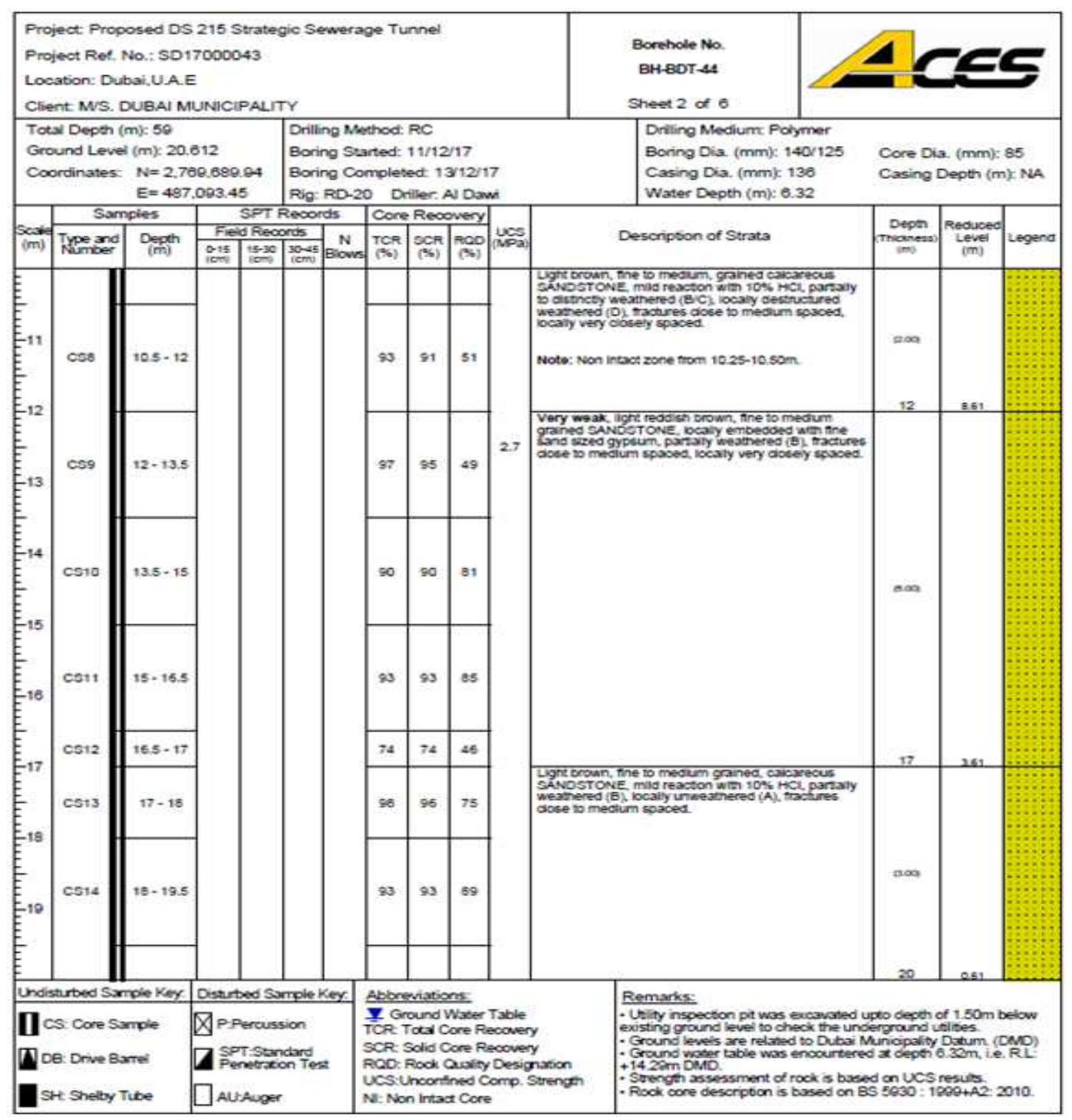

Figure 5: Example of Borehole Log, Output of the Field Collection at Borehole BDT-44. 


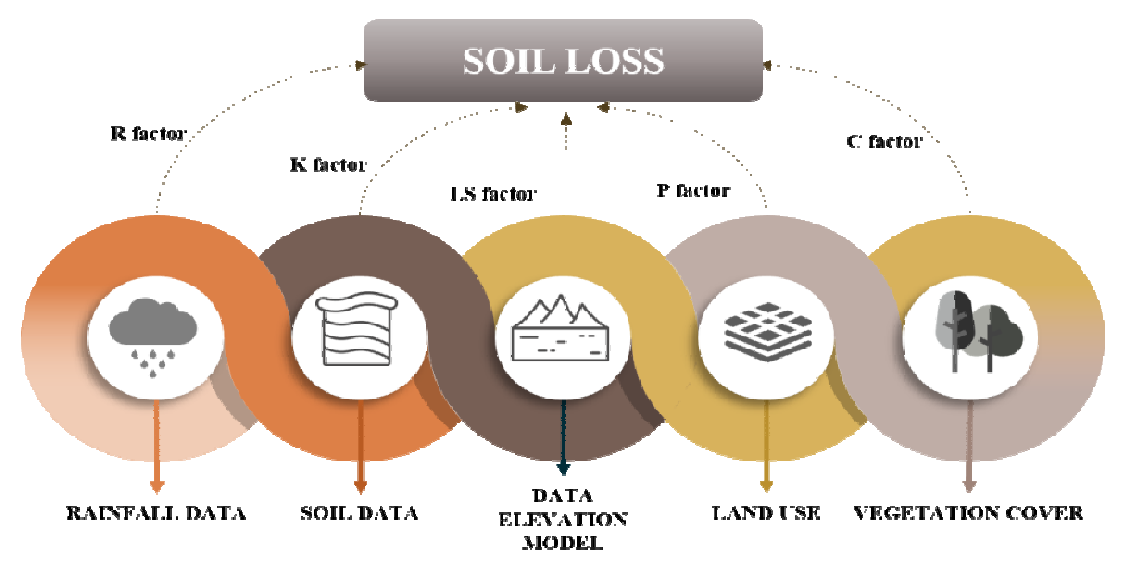

Figure 6: Flow Chart of the Applied RUSLE Model.

\section{Sample Analysis}

The Laboratory analysis was carried out for the soil samples collected during the field work while the groundwater well parameters were captured and stored within the enterprise geodatabase designed and managed by the drainage department at Dubai Municipality. All of the physical and chemical tests and analysis were carried out in the laboratory as per the Dubai standard procedures.

\section{Soil Erosion Modelling}

Models of soil erosion are available with different levels of complication. The theory chosen for soil erosion modelling is called RUSLE (Revised Universal Soil Loss Equation) where the factors captured are expressed as: A=1/4RKLSCPð2P. A represents the total yearly soil loss in tonnes per acre, per year from sheet, rill and inter-rill erosion; $\mathrm{R}$ represents the rainfall and run off factor; $\mathrm{K}$ represents the soil erodibility factor; LS represents the slope length and steepness factor; $\mathrm{C}$ is the land use and cover factor; and P represents the management support practice factor. This model supports the advanced analysis for the determination of dominant factors of soilerosion.

\section{Water Quality Estimation}

During the last thirty years, Hatta's ground water became at a risk of contamination, over-extraction and over-irrigation. Yet, the declining water quality and modest irrigation practices in many areas pressured local farmers to install packaged desalination equipments which caused a noticeable increase in the salinity levels in the surface water of the region, leading to contaminants percolation to the groundwater aquifers. Part of this project, Drainage Projects department at Dubai Municipality captured the ground water parameters for 47,000 wells and bore holes in Dubai during different time stamps which is considered as a comprehensive and necessary effort to fully understand the state of the groundwater resources in the Emirate especially in Hatta in order to support the development of effective policies and efficiently manage these resources.

In order to estimate the values of the water quality, it is necessary to use an advanced procedure that generates an estimated surface from a scattered set of points with these values, Kriging is best for such purpose, it is referred to as deterministic interpolation method because it is based on statistical models that include autocorrelation, that is, the statistical relationships among the measured sample points (IvanaMesićKiš, 2016). Such approach helped in this study not only to produce a prediction surface of water quality but also provide a measurement of the certainty and accuracy of the predictions. Kriging weights the surrounding measured values to derive a prediction for an unmeasured location. The 
general formula for both interpolators is formed as a weighted sum of the data:

$$
\begin{aligned}
& \hat{Z}\left(s_{0}\right)=\sum_{i=1}^{N} \lambda_{i} Z\left(s_{i}\right) \\
& Z_{(s i)}=\text { the measured value at the } i \text { th location } \\
& \lambda_{i}=\text { an unknown weight for the measured value at the } i \text { th location } \\
& s_{0}=\text { the prediction location } \\
& N=\text { the number of measured values }
\end{aligned}
$$

\section{RESULTS}

\section{Mapping RUSLE Parameters}

\section{Rain Erosive Factor (R)}

The major part of the catchment area is subject to medium/low rainfall aggressiveness, therefore $\mathrm{R}$ values do not exceed range of 20. Rainfall in both dams however, is associated with noticeable erosive power.

Table 2: Average of Rainfall Per year in $\mathrm{mm}^{3}$

\begin{tabular}{|c|c|c|}
\hline Year & Dam A & Dam B \\
\hline $\mathbf{2 0 1 2}$ & 50.90 & 42.20 \\
\hline $\mathbf{2 0 1 3}$ & 55.00 & 24.20 \\
\hline $\mathbf{2 0 1 4}$ & 59.40 & 15.80 \\
\hline $\mathbf{2 0 1 6}$ & 41.40 & 14.40 \\
\hline $\mathbf{2 0 1 7}$ & 62.00 & 15.80 \\
\hline $\mathbf{2 0 1 8}$ & 21.80 & 9.00 \\
\hline
\end{tabular}

\section{Soil Erodibility Factor $(\mathbf{K})$}

Soil erodibility is a complex factor to calculate, it is influenced by many soil properties that can cause soil erosion. The most important soil variables that control K-factor include clay content, bulk density, particle size distribution, shape, size and stability of aggregates, shear strength, porosity and permeability, and chemical composition.

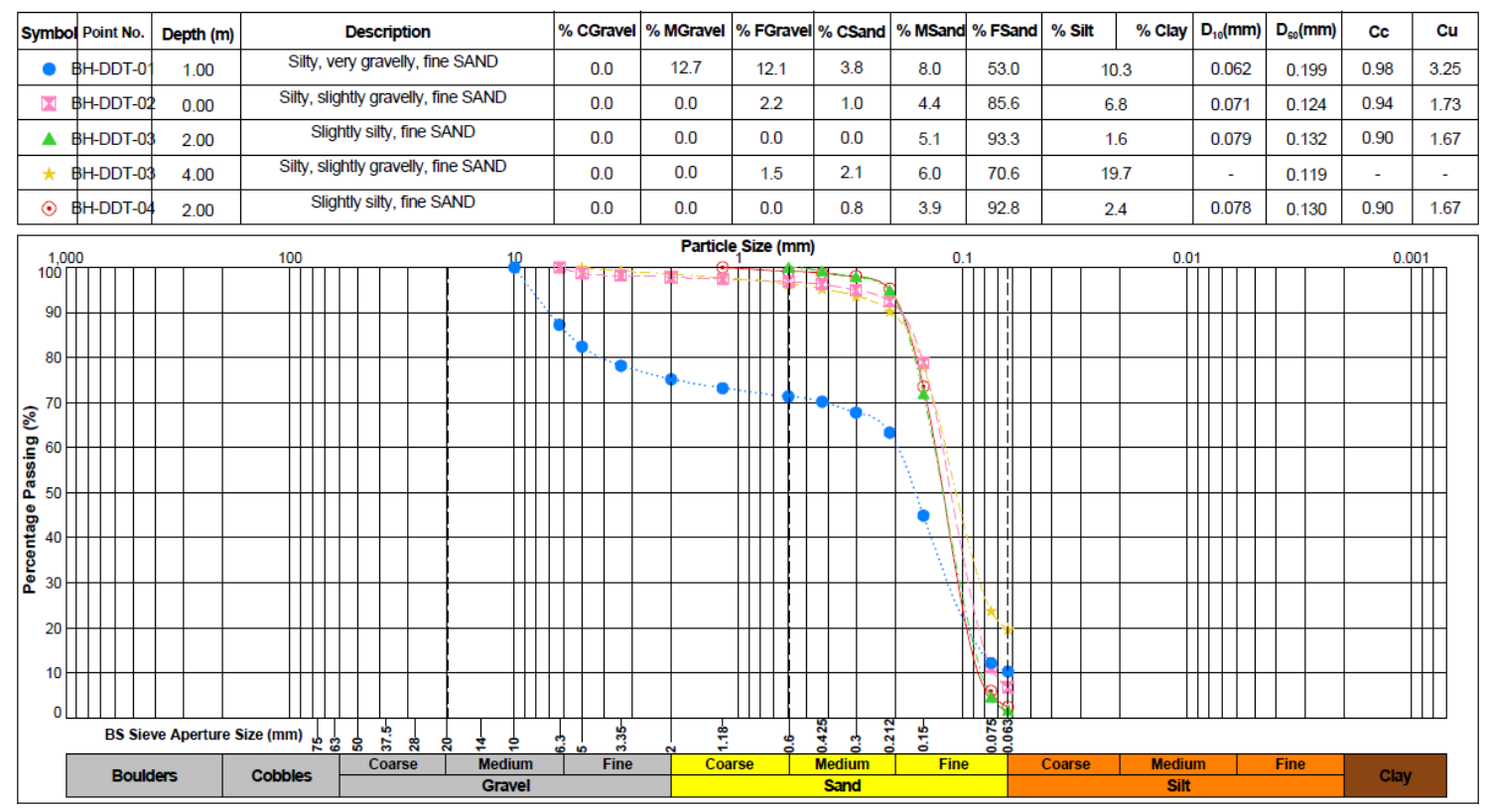

Figure 7: Particle Size Distribution of 4 Boreholes. 
Table 3: Permeability Testing Results Dam 1 Borehole Sample and K Factor Result

\begin{tabular}{|c|c|c|c|c|}
\hline $\mathbf{t}(\mathbf{m i n})$ & $\mathbf{Z}$ & $\mathbf{t}(\mathbf{s e c})$ & Variable Head measured at t, H (m) & H/H0 \\
\hline 0 & 0 & 0 & 2.9 & 1 \\
\hline 0.5 & 0.2 & 30 & 2.7 & 0.931 \\
\hline 1 & 0.3 & 60 & 2.6 & 0.897 \\
\hline 1.5 & 0.45 & 90 & 2.45 & 0.845 \\
\hline 2 & 0.55 & 120 & 2.35 & 0.81 \\
\hline 2.5 & 0.76 & 150 & 2.14 & 0.738 \\
\hline 3 & 0.94 & 180 & 1.96 & 0.676 \\
\hline 4 & 1.06 & 240 & 1.84 & 0.634 \\
\hline 5 & 1.11 & 300 & 1.79 & 0.617 \\
\hline 10 & 1.4 & 600 & 1.5 & 0.517 \\
\hline 15 & 1.71 & 900 & 1.19 & 0.41 \\
\hline 20 & 2 & 1200 & 0.9 & 0.31 \\
\hline 25 & 2.25 & 1500 & 0.65 & 0.224 \\
\hline 30 & 2.38 & 1800 & 0.52 & 0.179 \\
\hline 45 & 2.5 & 2700 & 0.4 & 0.138 \\
\hline 60 & 2.61 & 3600 & 0.29 & 0.1 \\
\hline 75 & 2.65 & 4500 & 0.25 & 0.086 \\
\hline 80 & 2.67 & 4800 & 0.23 & 0.079 \\
\hline 85 & 2.67 & 5100 & 0.23 & 0.079 \\
\hline \multicolumn{5}{|c|}{ Coefficient of Permeability (A/FT), K= } \\
\hline
\end{tabular}

\section{Topographic Factor (LS)}

Two main elements are considered by the RUSLE model: the length of the slope and the aspect. In fact, longer the slope is; the more runoff accumulates, the stronger erosion becomes.

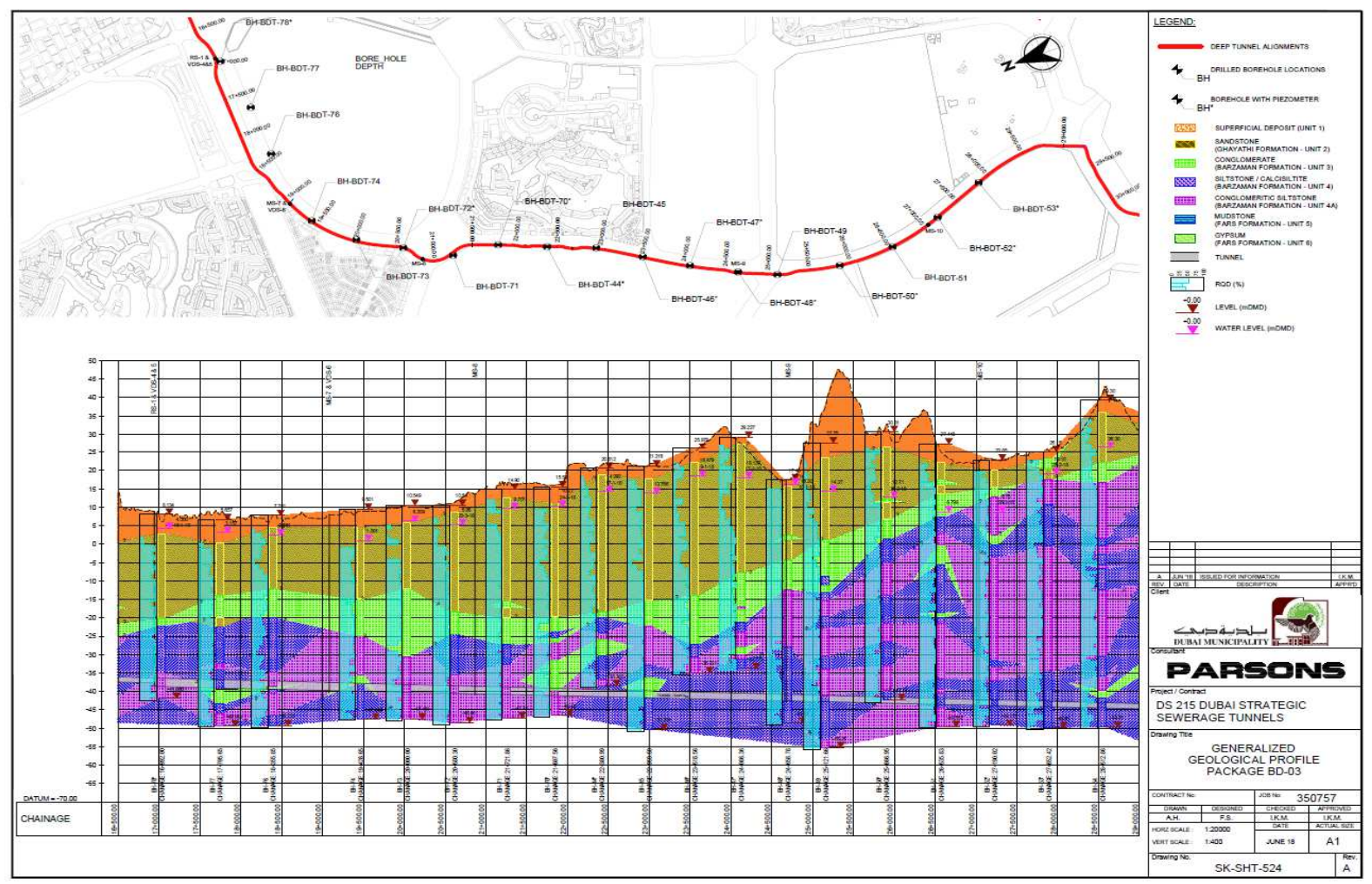

Figure 8. Boreholes Geological Profile with Water Depth and Soil Types Mapping. 


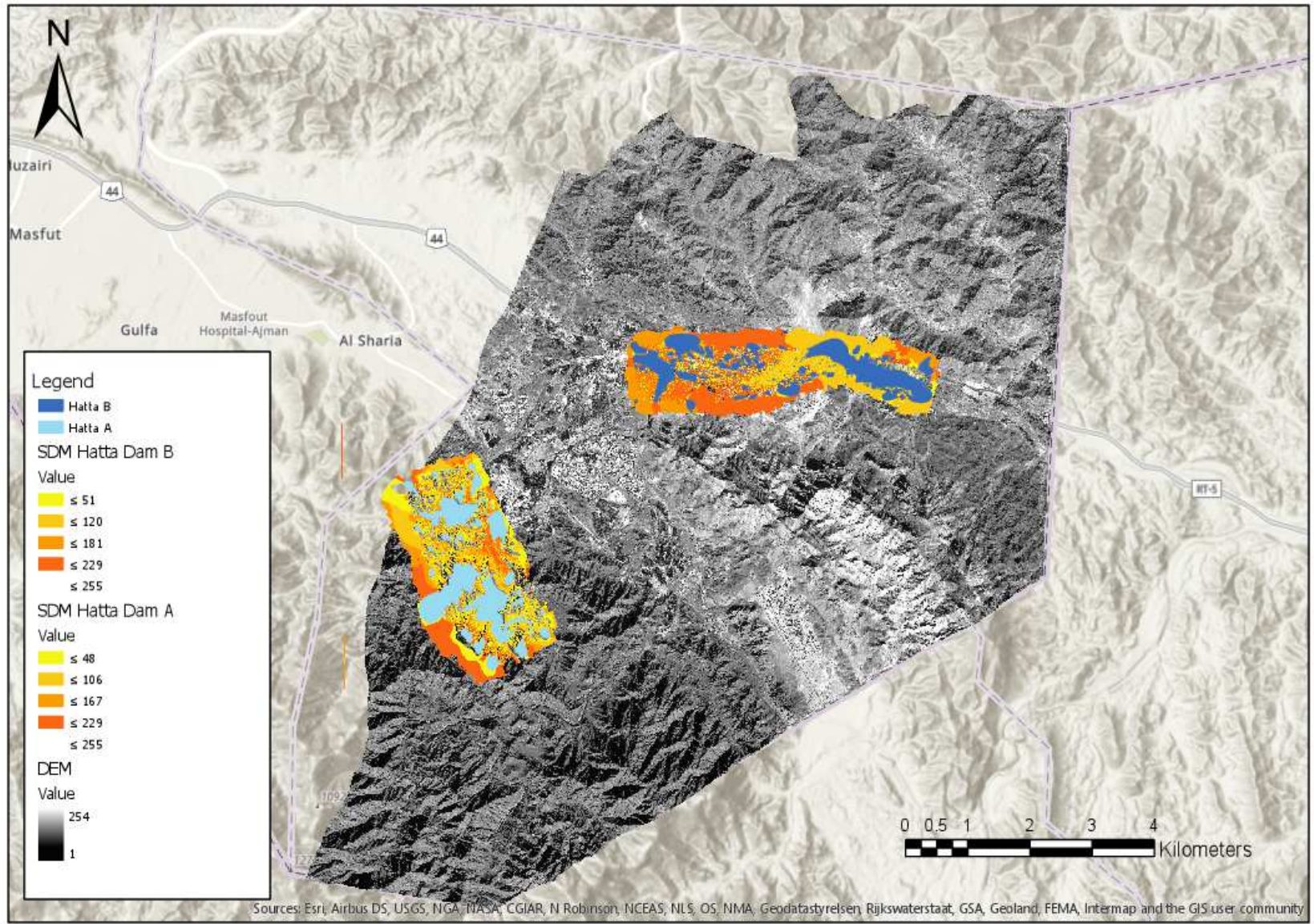

Figure 9: Data Elevation Model \& Surface Data Models for Hatta Dam \& Al Maktoum Dam

\section{Dam Vegetation Cover Factor $(\mathbf{C})$}

Dubai SAT, Worldview2 Satellite images with $60 \mathrm{~cm}$ resolution and PlanetScope1 mosaicked Surface Reflectance Basemap were used as data sources to analyze the vegetation cover of Dubai Emirate in general and Hatta region in particular. Figure 11 displays the vegetation health represented by the NDVI on a scale from 0 to 200. Greener pixels correspond to healthier vegetation. A peak in healthy vegetation was reached in March for both dams.
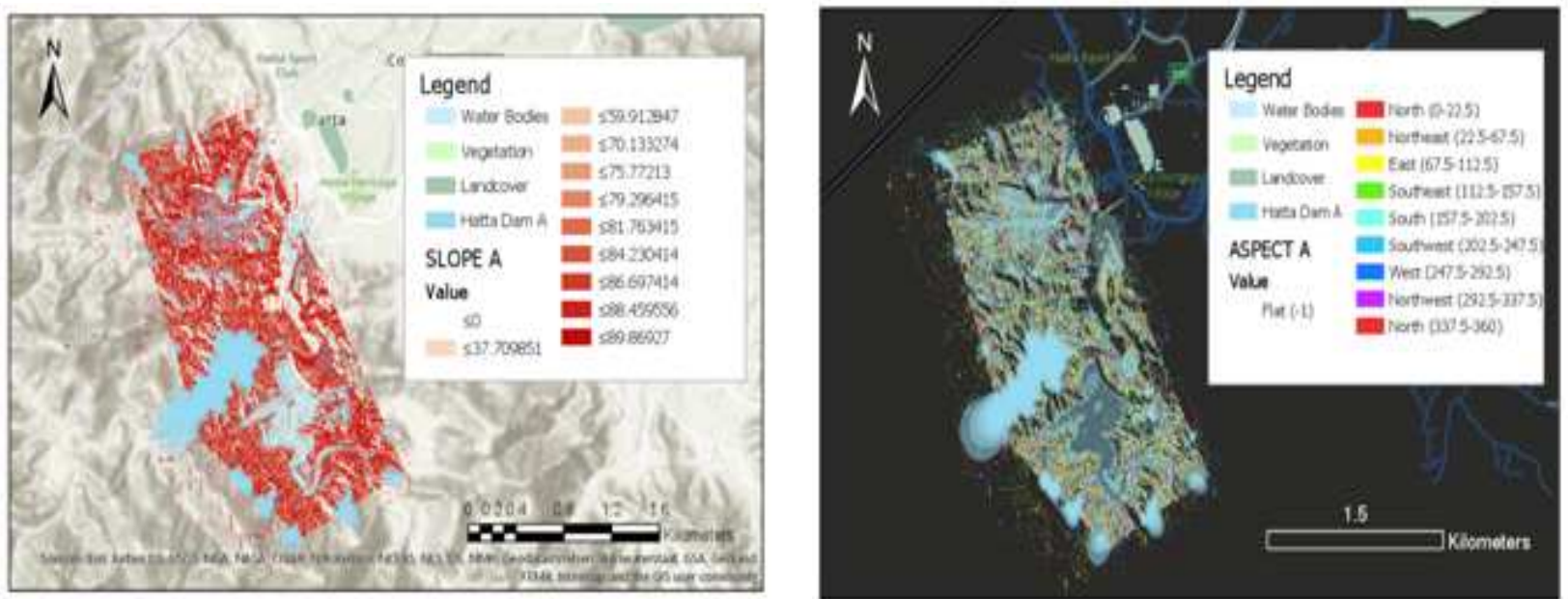

Figure 10: Slope and Aspect Results for Hatta Dam. 


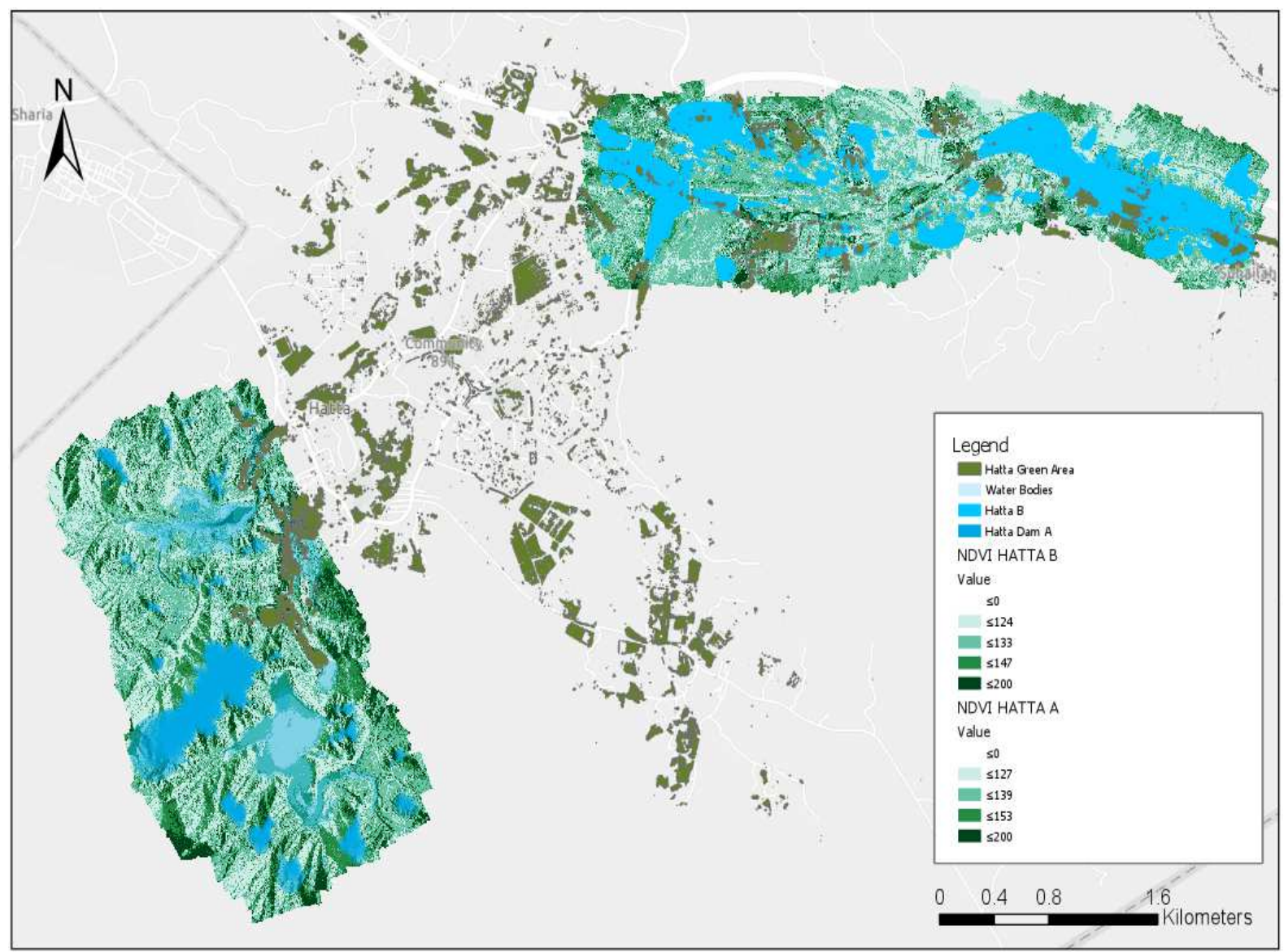

Figure 11: NDVI Representation at Both Dams Generated from Worldview2 Satellite Imagery $60 \mathrm{~cm}$, March 2018.

Figure 12 highlights the temperature and precipitation dependency of vegetation health in Dubai Emirate, the weather data (Temperature in ${ }^{\circ} \mathrm{C}$ and Precipitation in $10 \mathrm{~mm} / \mathrm{m} 2$ ) was supplied by Dubai International Airport Weather station.

\section{Cultural Practices Factor (P)}

P represents the management support practice factor where efforts of conservation against erosion are illustrated.

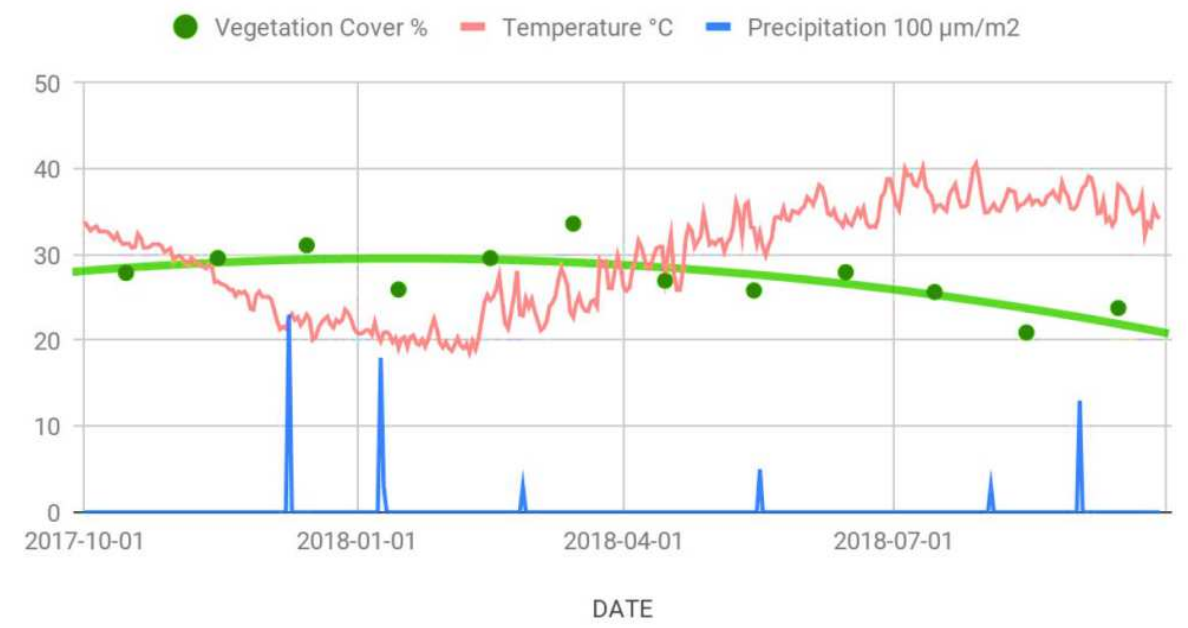

Figure 12: Percentage of Healthy Vegetation in Dubai Emirate over 12 Months. 


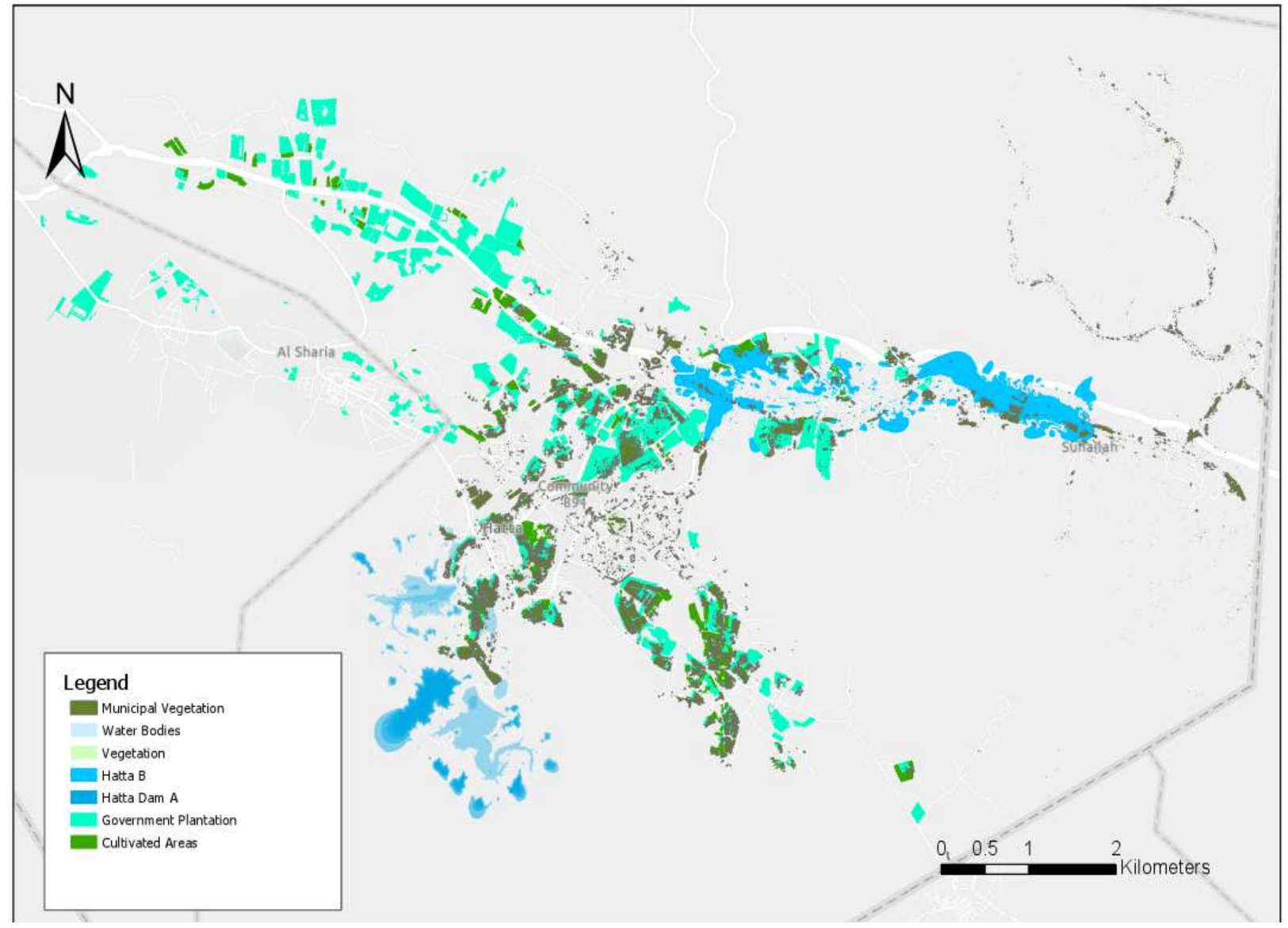

Figure 13: Mapping of Governmental Efforts of Plantation and Cultivation in Hatta Region.

\section{Soil Erosion Assessment}

The erosion indicator as RUSLE output for Hatta region varies between 0.056 and 28.2t/ ha/year with an average of 2.81 t/ha/year, which is considered low in remote areas and medium to high in areas surrounding both Hatta dams.

Figure 14 represents the RUSLE erosion over the study area on Hatta map, classified using the statistical trend of Natural Breaks.

\section{Water Quality Estimation}

Eroded soil material result in salinity increase emanating from waste water discharge which has caused the main water quality challenges in Hatta. Water ecosystem nutrients reduction causes diverse problems such as loss of oxygen, dying of fishes, and extreme loss of biodiversity. It also results in damage to water plants coral reefs and beds and creates water treatment problems.

The results of monitoring activities carried out by Dubai municipality teams in various study sites and depths of boreholes in Hatta, followed by hydrologic estimation and the tropic status estimation using GIS tools supported the mapping of water quality parameters and its representation in graphs and charts.

Figure 15 displays the estimated salinity distribution according to the six defined classes in the principal depths 0 to $25 \mathrm{~cm}, 25$ to $50 \mathrm{~cm}, 50$ to $100 \mathrm{~cm}$ and 100 to $150 \mathrm{~cm}$. 


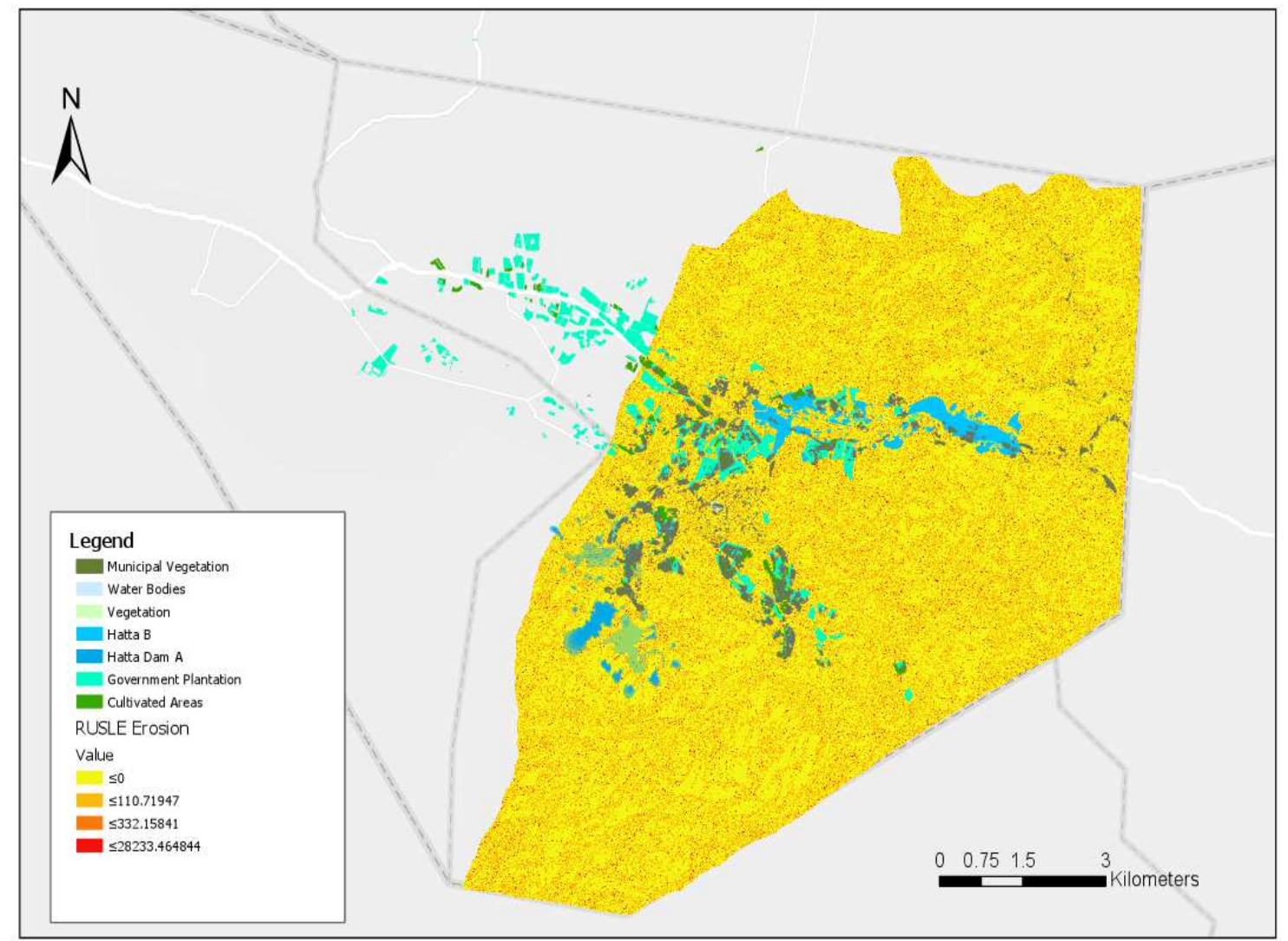

Figure 14: Mapping of Soil Erosion Impact in Hatta Region based on RUSLE and DEM Inputs.

The preliminary interpretation of the collected and processed data indicates that salinity distribution varies with depth and type of the soil profile encountered. Hatta region for instance contains middle class salinities due to the presence of well-drained sandy soils mixed with drainage impeding mainly calcareous soils.

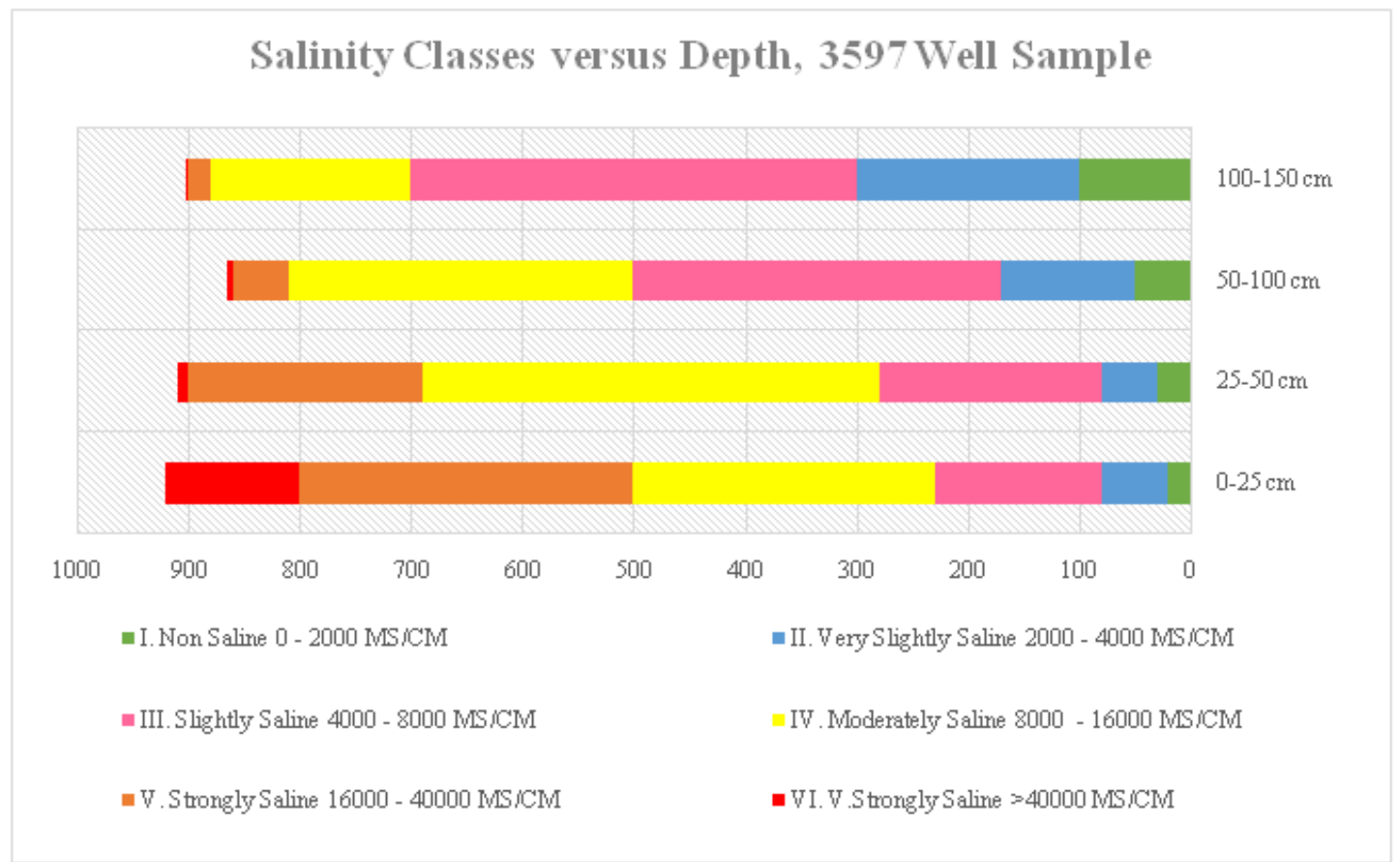

Figure 15: Salinity Distribution at 4 Standard Depths for Soils of 3597 Selected Well Samples. 


\section{CONCLUSIONS}

In Dubai, severe soil erosion is a major environmental challenge. During the past 30 years, the local government carried out a sophisticated program of ecological reconstruction where many approaches and best practices were tested to help control the soil and water erosion problems. Furthermore, UAE vision 2021 National Agenda focuses on improving the quality of air, preserving water resources, increasing the contribution of clean energy and implementing green growth plans. In order to achieve these goals, citizens, farmers, tourists, contractors, and many more should participate in abiding with policies, rules and regulations in all aspects to reduce and manage the soil and water degradation rates in the Emirate.

This research, combining advanced spatial analysis and RUSLE modelling of erosion, supports the identification of vulnerable are as to erosion and compare the same with water resources degradation; which is an essential tool for planning the conservation of natural resources in Hatta. The objective of this paper is to demonstrate the link between the actual soil and water erosion in Hatta and the degradation of available water resources using the RUSLE model and spatial analysis.

The results acquired on maps, charts, graphs and tables provide valuable support to decision-makers and management planners in order to simulate the evolution scenarios and eventually target priority areas that require rehabilitation measures for degraded areas.

\section{REFERENCES}

1. Liu, Y. (2016). Landscape connectivity in Soil Erosion Research: concepts, implication, quantification. Geographical Research, 1, 195to simManyevere, A., Muchaonyerwa, P., Mnkeni.

2. Al-Wadaey, A., \& Ziadat, F. (2014). A participatory GIS approach to identify critical land degradation areas and prioritize soil conservation for mountainous olive groves Muchaonyerwa, P., Mnkeniodel and spatince, 11,782, 11,

3. K. E. Kasapoglu, M. N. ToksK . (1983). Tectonic consequences of the collision of the Arabian and Eurasian plates (1983). Finite element models. Tectonophysics Volume 100, Issues 1su, December 1983, Pages 71-95.

4. Laflen, J. M., \& Flanagan, D. C. (2013). The development of U. S. soil erosion prediction and modeling. International Soil and Water Conservation Research, 1, 1-11.

5. Renard, K. G., Yoder, D. C., Lightle, D. T., \& Dabney, S. M. (2010). Universal soil loss equation and revised universal soil loss equation. Handbook of Erosion Modelling, 1, 137-167.

6. Ivana Mesii Me. (2016). Comparison of Ordinary and Universal Kriging interpolation techniques on a depth variable (a case of linear spatial trend), case study of the ing, 1, 137iodel and spatince, 11,782, 11,782d spatince, 11,7rowth plans. In o 912. DOI: $10.17794 /$ rgn.2016.2.4.

7. GT, A. (2018). People (2018). Peop of Soil Erosion and its Impact in Imo State, Nigeria. IMPACT: International Journal Of Research In Applied, Natural And Social Sciences (IMPACT: IJRANSS) ISSN (P), 2347-4580.

8. G. Buttafuoco, M. Conforti, P. P. C. Aucelli, G. Robustelli, F. Scarciglia. (2012). Assessing spatial uncertainty in mapping soil erodibility factor using geo statistical stochastic simulation. Environmental Earth Sciences, 66 (4) (2012), pp. 1111-1125.

9. S. W. Duiker, D. C. Flanagan, R. Lal, Erodibility and infiltration characteristics of five major soils of southwest Spain Catena, 45 (2) (2001), pp. 103-121.

10. Paroissien J. B., Darboux F., Couturier A., Devillers B., Mouillot F., Raclot D., Le Bissonnais Y. (2015). A method for modeling the effects of climate and land use changes on erosion and sustainability of soils in a Mediterranean watershed (Languedoc, France). Journal of Environmental Management 150 (2015) 57-68. 
11. Pushpalatha, K., Kumar, K., Rao, K., \& Rejani, R. (2017). Spatial and Temporal Variation of C of C on of C C l Variation of $C$ aariation of Spatial and Temial in Mahabubnagar District. International Journal of Agricultural Science and Research (IJASR), 7(5), 175-188.

12. Roose, E. (1976) Use of the Universal Soil Loss Equation to Predict Erosion in West Africa. In: Soil Erosion: Prediction and Control, SCSA, Special Publication No. 21, 60-74.

13. Mohsen Sherif, Mohamed Almulla, Ampar Shetty, Rezaul K. Chowdhurya (2014). Analysis of rainfall, PMP and drought in the United Arab Emirates. International Journal of Climatology. Int. J. Climatol. 34: 1318-1328.

14. Al-Rashed MF, Sherif MM. 2000. Water resources in the GCC countries: an overview. Water Resources Management 14(1): $59-75$.

15. Reshma, M. R., Duraisami, V. P., Muthumanickam, D., Purma, S., \& Jayasoorian, N. (2016). Delineation and Mapping of soil available Iron and Copper status in Soils of Salem district of Tamil Nadu Using GIS and GPS Techniques. International Journal of Agricultural Science and Research, 6(2), 295-300.

16. M, Ramachandra \& Kottala, Raghu B A\& M, Rajasekhar \& Badapalli, Pradeep. (2019). Lineament Analysis by Remote Sensing and GIS Techniques for Groundwater and Mineral Exploration in and around Lingala and Pendlimarri Mandal's of Kadapa District, A. P, India.

17. Food and Agriculture Organization of the United Nations. SOIL EROSION: the greatest challenge for sustainable soil management.

18. Telkar, Shivkumar\& S Pote, Neha. (2018). Soil Erosion: Types and Their Mechanism.

19. Adilmoussebbih, D., Souissi Mohamed, D., Abdelkader, L., \& Mohamed, F. Modeling and Mapping of the Water Erosion Risk using Gis/Rusle Approach in the Bouregreg River Watershed.

20. Alam, Afroz. (2014). Soil Degradation: A Challenge to Sustainable Agriculture. International Journal of Scientific Research in Agricultural Sciences. 1. 50-55. 10.12983/ijsras-2014-p0050-0055.

21. Crosson, Pierre \& Pimentel, David \& Harvey, Celia \& Resosudarmo, Ida \& Sinclair, $K \&$ Kurz, D\& McNair, M\& Crist, S \& Shpritz, L \& Fitton, L \& Saffouri, $R$ \& Blair, R. (1995). Soil Erosion Estimates and Costs. Science. 269. 461-465. 10.1126/science.269.5223.461.

22. Oldeman, L. R. \& Hakkeling, R. T. A. \& Sombroek, W. G. (1991). World map of the status of human-induced soil degradation: an explanatory note, 2 nd. rev. ed.

23. Mikola, Peitsa. (1979). The role of forestry in the fight against desertification. Silva Fennica. 1979. 13(3): 223-226. 13. 10.14214/sf. a14895.

24. Vikhe, S. D., \& Patil, K. A. (2016). Assessment of Soil Erosion in Sukhana Basin using USLE, GIS and remote sensing: A case study. International Journal of Civil, Structural, Environmental and Infrastructure Engineering Research and Development, 6(4), 71-78.

25. Tiziano Gomiero. Soil Degradation, Land Scarcity and Food Security: Reviewing a Complex Challenge. Sustainability 2016, 8, 281; doi: 10.3390/su8030281. 
